\title{
Detachment of methacrylate-embedded sections from microscope slides can be prevented by heating on hotplate
}

\author{
Yu Xiang and Zheng-Wei Yang* \\ *Correspondence: zwyang@nsmc.edu.cn

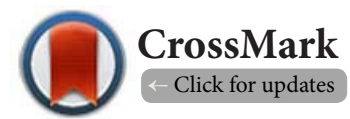

Morphometric Research Laboratory, North Sichuan Medical College, 234 Fujiang Road, Nanchong, Sichuan 637007, China.

\begin{abstract}
Glycol methacrylate (GMA, a resin also called 2-hydroxyethyl methacrylate) embedded sections are useful for quantitative (morphometric or stereological) study of histological structures, but detachment of sections (especially thick ones) from microscope slides is common during staining. We found that heating of the sections at a high temperature could prevent the section loss. To confirm our finding, we designed and conducted a series of experiments, comparing the numbers of sections detached after different treatments such as different temperatures $\left(90-290^{\circ} \mathrm{C}\right.$ ) of heating (on hotplate for 30 minutes), different slides (conventional and adhesive), and different thicknesses (10 and $20 \mu \mathrm{m})$ of sections. We showed that heating at $115-140^{\circ} \mathrm{C}$ prevented the GMA sections from detaching, with the light microscopic image unaffected.
\end{abstract}

Keywords: Detachment of sections, glycol methacrylate, histological structures, thickness of sections

\section{Introduction}

Glycol methacrylate (GMA), a resin or plastic also called 2-hydroxyethyl methacrylate, has been used for embedding and then sectioning of biological specimens for light microscopy since 1970s, yielding semi-thin sections morphologically superior to paraffin embedded sections [1,2]. Besides, GMA embedded sections have negligible or much less distortion or shrinkage of the tissue embedded, especially useful for quantitative (morphometric or stereological) study of histological structures [3]. With the necessity of thick sections for sampling or counting particles (e.g., nuclei or nucleoli) according to the method of optical disector in stereology [4], thick (e.g., 20-25 $\mu \mathrm{m}$ in thickness) GMA-embedded sections have become an essential part of contemporary stereological tools [3]. However, thick GMA sections were liable to detaching from microscope slides during staining. In managing to solve problems arising from our recent work with thick GMA sections [5], we found, to our surprise, that heating of the sections at a high temperature could prevent the detachment. A series of experiments were therefore designed and conducted in this study, using GMA-embedded testicular sections available in our laboratory, to confirm the finding and determine a heating temperature that would not only prevent section detachment but also maintain section quality.

\section{Materials and methods}

10 testicular tissue blocks of similar sizes, obtained from normal male Sprague-Dawley rats (age 8 weeks), were embedded in GMA (Historesin by Leica Microsystems Nussloch GmbH, Germany); 10-30 sections were cut from each block at a set thickness of 10 or $20 \mu \mathrm{m}$ using a microtome (RM2235, Leica Biosystems Nussloch $\mathrm{GmbH}$ ), with the average areas of the tissue sections and the entire sections (including the tissue and the GMA around the tissue) being approximately 24 and $64 \mathrm{~mm}^{2}$, respectively. The sections were randomly assigned to different experiments with different treatments such as different temperatures $\left(90-290^{\circ} \mathrm{C}\right)$ of heating of sections, different slides (conventional slides, and adhesive slides with positively charged surface produced by Yifan Experiment, China), and different procedures of staining, see Tables 1 and 2.

Our protocol of sections staining was as follows: 30 minutes in $1 \%$ periodic acid, $1 \times 3$ minutes (i.e., 1 minute for 3 times) in distilled water, 50 minutes in Schiff's reagent, 10 minutes in running tap water, 1 minute in distilled water, 30 minutes in hematoxylin, a few seconds in running tap water, 10 minutes in tap water, 1 minute in distilled water, 2 minutes in $70 \%$ ethanol (this step of dehydration was omitted in 1 experiment, see Table 1), 2 minutes in $95 \%$ ethanol, $2 \times 2$ minutes in absolute ethanol, 
Xiang et al. Journal of Histology \& Histopathology 2014,

http://www.hoajonline.com/journals/pdf/2055-091X-1-10.pdf

doi: 10.7243/2055-091X-1-10

Table 1. Number of sections detached after heating at different temperatures.

\begin{tabular}{l|l|l|l|l|l|l}
\hline & \multicolumn{4}{c|}{ Experiment 1 } & \multicolumn{2}{c}{ Experiment 2 } \\
\hline & \multicolumn{2}{|c|}{ Staining without 70\% ethanol } & \multicolumn{2}{c}{ Staining with 70\% ethanol } & \multicolumn{2}{c}{ Staining with 70\% ethanol } \\
\hline & Not detached & Detached & Not detached & Detached & Not detached & Detached \\
\hline $90^{\circ} \mathrm{C}$ & $5^{\mathrm{a}}$ & $5^{\mathrm{a}}$ & $0^{\mathrm{a}}$ & $10^{\mathrm{a}}$ & - & - \\
$140^{\circ} \mathrm{C}$ & $10^{\mathrm{b}}$ & $0^{\mathrm{b}}$ & $6^{\mathrm{b}}$ & $4^{\mathrm{b}}$ & 14 & 6 \\
$190^{\circ} \mathrm{C}$ & 5 & 0 & 5 & 0 & 6 & 0 \\
$240^{\circ} \mathrm{C}$ & 5 & 0 & 5 & 0 & 6 & 0 \\
$290^{\circ} \mathrm{C}$ & - & - & - & - & 6 & 0 \\
\hline
\end{tabular}

In Experiments 1 and 2, glycol methacrylate embedded testicular sections (cut at a set thickness of $20 \mu \mathrm{m}$ and mounted onto conventional slides) were placed on a hotplate at $90-290^{\circ} \mathrm{C}$ for 30 minutes before staining (periodic acid-Schiff's reagent and hematoxylin), which was not or was followed by dehydration in $70 \%$ ethanol for 2 minutes. $\mathrm{P} \leq 0.05$ for the contingency table data a or b (Fisher exact test).

Table 2. Number of sections detached in experiment 3.

\begin{tabular}{lll}
\hline & Not detached & Detached \\
\hline $90^{\circ} \mathrm{C}$, conventional slides, $10 \mu \mathrm{m}^{\mathrm{a}}$ & 13 & 7 \\
$90^{\circ} \mathrm{C}$, conventional slides, $20 \mu \mathrm{m}^{\mathrm{b}}$ & 2 & 18 \\
$90^{\circ} \mathrm{C}$, adhesive slides, $20 \mu \mathrm{m}^{\mathrm{c}}$ & 4 & 16 \\
$115^{\circ} \mathrm{C}$, conventional slides, $10 \mu \mathrm{m}^{\mathrm{d}}$ & 20 & 0 \\
$115^{\circ} \mathrm{C}$, conventional slides, $20 \mu \mathrm{m}^{\mathrm{e}}$ & 15 & 5 \\
$115^{\circ} \mathrm{C}$, adhesive slides, $20 \mu \mathrm{m}^{\mathrm{f}}$ & 14 & 6 \\
\hline
\end{tabular}

In Experiment 3, conventional or adhesive glass slides were used to mount the glycol methacrylate embedded testicular sections, which were cut at $10 \mu \mathrm{m}$ or $20 \mu \mathrm{m}$ (thickness) and heated on a hotplate at $90^{\circ} \mathrm{C}$ or $115^{\circ} \mathrm{C}$ for 30 minutes before staining with periodic acid-Schiff's reagent and hematoxylin followed by dehydration in $70 \%$ ethanol for 2 minutes. $x^{2}$ test: $\mathrm{P}<0.001$ for the contingency table data of $\mathrm{a}, \mathrm{b}$ and $\mathrm{c} ; \mathrm{P} \leq 0.05$ for $\mathrm{d}$, e and $\mathrm{f}$. $x^{2}$ test (Yates correction for continuity used): $\mathrm{P}>0.05$ for the contingency table data of $b$ and $c, d$ and $e$, or e and $f ; P \leq 0.05$ for $\mathrm{a}$ and $\mathrm{b}$, a and $\mathrm{d}, \mathrm{b}$ and $\mathrm{e}$, or $\mathrm{c}$ and $\mathrm{f}$.

and $2 \times 2$ minutes in xylene. Before staining, sections were heated on a hotplate (H17.5D, Ingenieurbüro, M. Zipperer $\mathrm{GmbH}$, Germany) for 30 minutes. Care was taken to ensure that the bottom surface of the glass (slide), not the upper surface on which the section was mounted, was put on the surface of the hotplate. After staining, they were mounted with a neutral balsam.

Detachment of a section was defined in this study as fully detaching of the section from the glass slide on which the section was mounted, i.e., the section fell off (or became separated from) the slide during staining.

Thickness of some sections (Tables 1 and $\mathbf{3}$ ) were measured after staining. As we previously described [6], the section was observed on a computer screen (final magnification $\times 2240$ ), using a $\times 100$ oil lens (UPlanSApo, NA 1.40, Olympus, Japan) on an Olympus BX51 microscope equipped with a stereology image system (Visiopharm, Denmark); 10 fields (distance between fields $1000 \mu \mathrm{m}$ ) were sampled per section in a systematic random manner; a frame ( $35 \mu \mathrm{m} \times 26 \mu \mathrm{m})$ was superimposed at the center of each field; the upper surface of the section was first brought into focus within the frame area, and then the bottom surface was focused within the frame area; the distance between the 2 focal planes, which was measured by a microcater (Dr. Johannes Heidenhain $\mathrm{GmbH}$, Germany) and shown on the screen, was a thickness of the section at the frame area. For thickness measurement of the thinner stained section (Table 3 ), the bottom surface in focus was the bottom surface of the stained structures (especially nuclei) whose shapes could be clearly seen, not the bottom surface of the embedding medium.

Table 3. Thickness ( $\mu \mathrm{m}, \overline{\mathrm{X}} \pm \mathrm{SD}$, median, range) of sections after heating at different temperatures.

\begin{tabular}{|c|c|c|}
\hline & GMA sections & Thinner stained sections \\
\hline $90^{\circ} \mathrm{C}$ & $\begin{array}{l}19.8 \pm 0.6,19.6,18.7-20.9 \\
(\mathrm{n}=10)\end{array}$ & $-\left(n^{\prime}=0\right)$ \\
\hline $140^{\circ} \mathrm{C}$ & $\begin{array}{l}19.8 \pm 1.1,19.7,18.4-22.6 \\
(n=10)\end{array}$ & $\begin{array}{l}18.2 \pm 1.5,17.8,16.3-21.4 \\
\left(n^{\prime}=10\right)^{*}\end{array}$ \\
\hline $190^{\circ} \mathrm{C}$ & $\begin{array}{l}19.0 \pm 0.7,19.0,17.4-20.1 \\
(\mathrm{n}=11)\end{array}$ & $\begin{array}{l}13.2 \pm 2.0,12.7,10.9-17.1 \\
\left(n^{\prime}=11\right)^{\#{ }^{*}}\end{array}$ \\
\hline $240^{\circ} \mathrm{C}$ & $\begin{array}{l}18.6 \pm 0.7,18.7,17.3-19.4 \\
(\mathrm{n}=11)^{\#}\end{array}$ & $\begin{array}{l}5.4 \pm 6.0,4.8,0.0-17.2 \\
\left(\mathrm{n}^{\prime}=11\right)^{\#^{*}}\end{array}$ \\
\hline $290^{\circ} \mathrm{C}$ & $\begin{array}{l}12.9 \pm 4.5,12.1,8.7-18.5 \\
(\mathrm{n}=6)^{\#}\end{array}$ & $\begin{array}{l}0.1 \pm 0.4,0.0,0.0-0.9 \\
\left(n^{\prime}=6\right)^{\#^{*}}\end{array}$ \\
\hline
\end{tabular}

$\mathrm{n}$ is the number of glycol methacrylate embedded testicular sections cut at a set thickness of $20 \mu \mathrm{m}$. A thinner stained section is part of the entire GMA section with stained histological structures, whose thickness is thinner than that of the entire section; n' is the number of thinner stained sections. ${ }^{*} P \leq 0.05$ for comparison with the thickness at $140^{\circ} \mathrm{C}$ in the "GMA sections" or "Thinner stained sections" group. [As normality test failed $(\mathrm{P}<0.01)$, Kruskal-Wallis one way analysis of variance on ranks was used, in combination with the Dunn's method for comparison of the " $140^{\circ} \mathrm{C}$ " subgroup with each of the other subgroups.] ${ }^{\star} \mathrm{P}<0.001$ for thickness comparison between "GMA sections" and "Thinner stained sections" (one-tail paired t-test). 
Xiang et al. Journal of Histology \& Histopathology 2014,

http://www.hoajonline.com/journals/pdf/2055-091X-1-10.pdf

\section{Results}

With heating of sections (thickness $20 \mu \mathrm{m}$ ) at $90^{\circ} \mathrm{C}$, half (without dehydration in $70 \%$ ethanol after staining) or all (with dehydration in $70 \%$ ethanol) of the sections detached from slides before mounting (Table 1). When the heating temperature increased to $115^{\circ} \mathrm{C}$ or $140^{\circ} \mathrm{C}$, no sections (without dehydration in $70 \%$ ethanol) or less than half of the sections (with dehydration in 70\% ethanol) detached (Tables 1 and 2). At $190^{\circ} \mathrm{C}$ or higher heating temperatures, detachment of sections was completely prevented (Table 1).

Detachment occurred in fewer thinner sections (thickness $10 \mu \mathrm{m}$ ) compared to thicker ones (thickness $20 \mu \mathrm{m}$ ), and none of the thinner sections detached after heating at temperature $115^{\circ} \mathrm{C}$ (Table 2). In contrast, the use of adhesive slides did not show significant effect on the prevention of sections detachment (Table 2).

Detachment of sections occurred after staining with periodic acid-Schiff's reagent (PAS) and hematoxylin. For more than $80 \%$ of the sections detached, it occurred at the step of dehydration in $70 \%$ ethanol (if there was this step in the staining) or in $95 \%$ ethanol (if there was not the step of dehydration in $70 \%$ ethanol).

In regard to the microscopic effect or quality, staining followed by dehydration in $70 \%$ ethanol, in comparison with staining without this step of dehydration, appeared to offer a slightly clearer section image. With increasing heating temperatures, the sections were stained increasingly lighter (Figure 1); at $290^{\circ} \mathrm{C}$, only the shade of the structures was seen. In parallel, the embedding medium and, in particular, the tissue section embedded in the medium became thinner and thinner beyond $140^{\circ} \mathrm{C}$; at $290^{\circ} \mathrm{C}$, almost no structures were stained (Table 3). Poor staining of the tissue section started from its bottom surface on the slide. That is, the burning effect on the upper part of the section happened later. However, heating of sections up to even $240^{\circ} \mathrm{C}$ did not appear to induce appreciable changes in the size or shape of structures (nuclei or tissues) that were stained and seen.

\section{Discussion}

GMA sections, often obtained with semi-thin thickness (e.g., 1-2 $\mu \mathrm{m}$ ), were usually left to dry up, e.g., at room temperature overnight [7] or at $50-70^{\circ} \mathrm{C}$ for $1-4$ hours $[8,9]$, to ensure their adhesion to slides. But for thick GMA sections, their detachment from slides is a common problem. We have found in this study that this problem can be effectively solved by heating them on a hotplate at higher temperatures.

Based on the limited experiments in the current study, we recommend a heating temperature of $115-140^{\circ} \mathrm{C}$ (for $30 \mathrm{mi}-$ nutes) for detachment prevention of thick (10-20 $\mu \mathrm{m}) \mathrm{GMA}$ sections (Tables 1 and 2). For sections less than $10 \mu \mathrm{m}$ in thickness, $90^{\circ} \mathrm{C}$ (30 minutes) may be enough. Importantly, the morphology of the tissue structures or the thickness of the tissue sections (Table 3 ) was essentially unaffected by heating at these temperatures, suggesting that the embedding medium

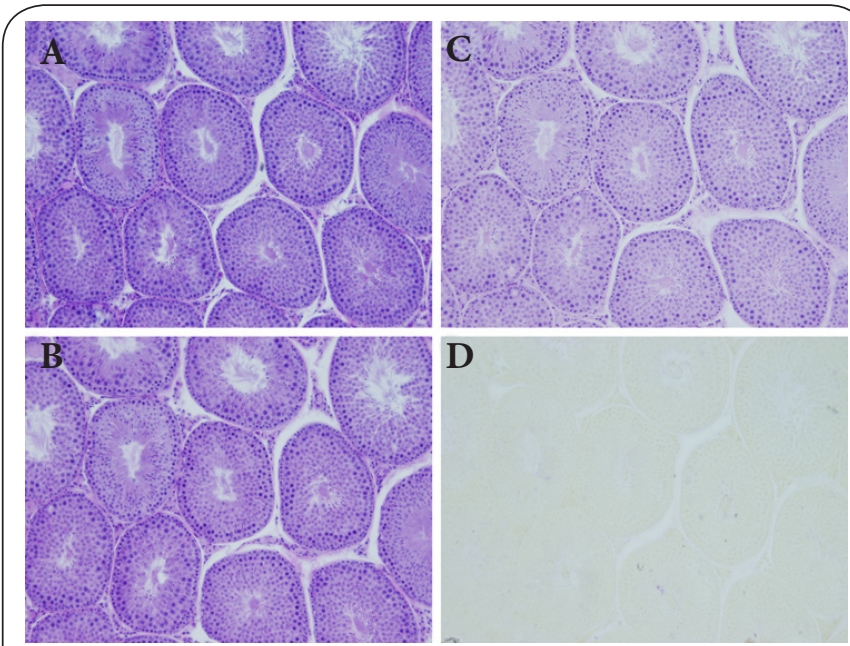

Figure 1. Testicular micrographs (each with width $870 \mu \mathrm{m}$ ) taken from the focal plane at the upper surface of $20 \mu \mathrm{m}$ thick GMA sections, which were heated, before staining with periodic acid-Schiff's reagent and hematoxylin followed by dehydration in $70 \%$ ethanol, at $90^{\circ} \mathrm{C}(\mathbf{A}), 140^{\circ} \mathrm{C}(\mathbf{B}), 190^{\circ} \mathrm{C}(\mathrm{C})$ and $240^{\circ} \mathrm{C}$ (D) for 30 minutes, respectively.

GMA, which was not dissolved or removed during staining, served as a good protection for the tissue embedded.

Apart from GMA-embedded testicular sections used in this study, as shown in our recent experience, the heating method also applies to GMA-embedded sections of the rat eye, seminal vesicle and spinal cord for effective prevention of section detachment. Whether the immunohistochemical staining will be affected by the heating, however, remains to be further studied. The study of paraffin sections (see below) suggests that it may be affected.

The experimental designs in the current study did not demonstrate a significant effect of adhesive slides on the affixing of GMA sections to slides (see Table 2). Although this does not necessarily mean that adhesive slides have no use for GMA sections, we can rest assured that the use of adhesive slides is not as effective as the heating of slides for the prevention of GMA sections detachment.

According to our years of experience, as also shown in the current study, detachment of GMA sections occurs frequently at the step of dehydration in $70 \%$ ethanol after staining. This procedure was designed in this study in order to obtain contrasting results. As expected, we obtained efficient results with statistical significance using limited numbers of sections and experiments (Tables 1 and 2).

With respect to paraffin sections, according to our additional study (data not reported), heating (after dewaxing) of paraffin embedded renal and spinal cord sections at $90-140^{\circ} \mathrm{C}$ prevented detachment of sections, but resulted in not only marked reduction of the section thickness but also marked damage to the sections, including disappearance or poor staining of some nuclei, and more non-specific immunohistochemical staining and fewer immuno-positive structures. Similarly, dec- 
Xiang et al. Journal of Histology \& Histopathology 2014,

http://www.hoajonline.com/journals/pdf/2055-091X-1-10.pdf

doi: 10.7243/2055-091X-1-10

reased intensity of immunostaining was previously reported after heating at $80^{\circ} \mathrm{C}$ for 16 hours [10]. Thus the implication is that the high temperature heating method does not apply to paraffin sections.

\section{Competing interests}

The authors declare that they have no competing interests.

Authors' contributions

\begin{tabular}{|l|c|c|}
\hline Authors' contributions & YX & ZWY \\
\hline Research concept and design & -- & $\checkmark$ \\
\hline Collection and/or assembly of data & $\checkmark$ & -- \\
\hline Data analysis and interpretation & -- & $\checkmark$ \\
\hline Writing the article & -- & $\checkmark$ \\
\hline Critical revision of the article & -- & $\checkmark$ \\
\hline Final approval of article & -- & $\checkmark$ \\
\hline Statistical analysis & -- & $\checkmark$ \\
\hline
\end{tabular}

Acknowledgement and funding

This study was supported by a grant from the Research

Development Program of North Sichuan Medical College

(CBY13-A-QN35).

\section{Publication history}

Editor: Khin Thway, The Royal Marsden Hospital, UK.

EIC: Giuseppe Musumeci, University of Catania, Italy.

Received: 12-Aug-2014 Final Revised: 16-Sep-2014

Accepted: 09-Oct-2014 Published: 16-Oct-2014

\section{References}

1. Bennett HS, Wyrick AD, Lee SW and McNeil JH. Science and art in preparing tissues embedded in plastic for light microscopy, with special reference to glycol methacrylate, glass knives and simple stains. Stain Technol. 1976; 51:71-97. | Article | PubMed

2. Litwin JA. Light microscopic histochemistry on plastic sections. Prog Histochem Cytochem. 1985; 16:1-84. | Article | PubMed

3. Yang ZW. Essential Tools for Morphometric Studies of Biological Tissues: Practical Stereological Methods. Beijing: Science Press. 2012.

4. Gundersen HJ, Bagger P, Bendtsen TF, Evans SM, Korbo L, Marcussen $\mathrm{N}$, Moller A, Nielsen K, Nyengaard JR, Pakkenberg B and et al. The new stereological tools: disector, fractionator, nucleator and point sampled intercepts and their use in pathological research and diagnosis. APMIS. 1988; 96:857-81. | Article | PubMed

5. Yang ZW, Xiang Y, Guo Y, Peng B, Bai GQ, Dong XT, Huang XL, Ma L, Chen J, Du $X$ and $Z$ hang SH. Moistening in a wet box of embedded tissue blocks stored for long can prevent or reduce tissue section breaking. Journal of North Sichuan Medical College. 2014; 29:492-493.

6. Peng B, Chen MS, Li H and Yang ZW. Comparison of the compressions of paraffin-embedded sections from different organs. Chinese Journal of Stereology and Image Analysis. 2012; 17:219-225.

7. Casey TT, Cousar JB and Collins RD. A simplified plastic embedding and immunohistologic technique for immunophenotypic analysis of human hematopoietic and lymphoid tissues. Am J Pathol. 1988; 131:183-9. I Article | PubMed Abstract | PubMed Full Text

8. Dancey JT, Deubelbeiss KA, Harker LA and Greenaway J. Section preparation of human marrow for light microscopy. J Clin Pathol. 1976; 29:704-10. | Article | PubMed Abstract | PubMed Full Text

9. Mason $M$ and Mackie RM. Comparative study of three methods of plastic embedding in diagnostic dermatopathology. J Clin Pathol. 1985; 38:1397-9. | Article | PubMed Abstract | PubMed Full Text

10. Jones WT, Stockard CR and Grizzle WE. Effects of time and temperature during attachment of sections to microscope slides on immunohistochemical detection of antigens. Biotech Histochem. 2001; 76:55-8. | Article | PubMed

\section{Citation:}

Xiang Y and Yang Z-W. Detachment of methacrylate-embedded sections from microscope slides can be prevented by heating on hotplate. J Histol Histopathol. 2014; 1:10. http://dx.doi.org/10.7243/2055-091X-1-10 